\title{
Competing Fragmentation Processes in Tandem Mass Spectra of Heparin-Like Glycosaminoglycans
}

\author{
Estee F. Naggar, Catherine E. Costello, and Joseph Zaia \\ Department of Biochemistry, Boston University School of Medicine, Boston, Massachusetts, USA
}

\begin{abstract}
Heparin-like glycosaminoglycans (HLGAGs) are highly sulfated, linear carbohydrates attached to proteoglycan core proteins and expressed on cell surfaces and in basement membranes. These carbohydrates bind several families of growth factors and growth factor receptors and act as coreceptors for these molecules. Tandem mass spectrometry has the potential to increase our understanding of the biological significance of HLGAG expression by providing a facile means for sequencing these molecules without the need for time-consuming total purification. The challenge for tandem mass spectrometric analysis of HLGAGs is to produce abundant ions derived via glycosidic bond cleavages while minimizing the abundances of ions produced from elimination of the fragile sulfate groups. This work describes the competing fragmentation pathways that result from dissociation of high negative charge state ions generated from HLGAGs. Glycosidic bond cleavage ion formation competes with losses of equivalents of $\mathrm{H}_{2} \mathrm{SO}_{4}$, resulting in complex ion patterns. For the most highly sulfated structure examined, an octasulfated tetramer, an unusual loss of charge from the precursor ion was observed, accompanied by low abundance ions originating from subsequent backbone cleavages. These results demonstrate that fragmentation processes competing with glycosidic bond cleavages are more favored for highly sulfated HLGAG ions. In conclusion, reduction of charge-charge repulsions, such as is achieved by pairing the HLGAG ions with metal cations, is necessary in order to minimize the abundances of ions derived via fragmentation processes that compete with glycosidic bond cleavages. (J Am Soc Mass Spectrom 2004, 15, 1534-1544) (C) 2004 American Society for Mass Spectrometry
\end{abstract}

$\mathrm{H}$ eparin-like glycosaminoglycans (HLGAGs) are the most highly sulfated oligosaccharides of the glycosaminoglycan family, consisting of repeating disaccharide units of [HexA $\beta / \alpha(1,4) \operatorname{GlcN} \beta(1,4)]$ that contain variable sulfation, commonly $2-3$ sulfate groups. HLGAGs are expressed on animal cell surfaces, in basement membranes and mast cell granules and play roles in blood coagulation, cellular proliferation, and interactions with fibroblast growth factors [1-3]. Sequence determination, including localization of sulfate groups on HLGAGs, is of significant interest, as their biological activities are believed to be expressed through patterns of sulfation and uronic acid epimerization $[4,5]$.

HLGAGs have traditionally proven difficult to analyze using mass spectrometry. Efforts to analyze these molecules using fast atom bombardment MS resulted in the observation of losses of $\mathrm{SO}_{3}$ and $\mathrm{NaSO}_{3}$ from the precursor ion, in addition to glycosidic bond cleavage ions [6-10]. The poor sensitivity, relative to that

Published online September 18, 2004

Address reprint requests to Dr. J. Zaia, Department of Biochemistry, Boston University School of Medicine, 715 Albany Street, R-806, Boston, MA 02118-2526, USA. E-mail: jzaia@bu.edu achieved for peptides of comparable size, and lack of an intact precursor ion meant that tandem MS was not a viable analysis option when FAB ionization was employed. Although HLGAGs produce weak signals by matrix-assisted laser desorption/ionization (MALDI), much more abundant ions are detected from complexes between these molecules and a basic peptide [11-13]. In conjunction with enzymatic and/or chemical degradation, this MALDI sample preparation technique has been effectively used to sequence highly purified HLGAGs [14-17]. Because the ions are detected in the positive mode, however, the charge is carried by the basic peptide and tandem MS of the HLGAG is not possible.

Because HLGAGs and other sulfated carbohydrates produce abundant negative ions using electrospray ionization (ESI) without requiring basic peptide complexation [18-20], tandem ESI-MS is feasible. Negative ESI tandem MS studies of chondroitin sulfate oligosaccharides have shown that the product ion pattern depends strongly on the charge state of the precursor ion [21, 22]. Specifically, it was shown that ions for which all sulfate groups are deprotonated fragment to produce abundant glycosidic bond cleavages without losses of the sulfate groups. Ions with lower charge states, for which some of the sulfate groups remain 
protonated, yield abundant fragment ions through losses of $\mathrm{SO}_{3}$. HLGAGs, however, contain a high density of sulfate groups and ions are formed in which some of these remain protonated. Therefore, tandem MS results in cleavages to both glycosidic bonds and sulfate groups, giving rise to complex spectral patterns [23].

The goal of this research is to sequence HLGAG oligosaccharides using tandem MS. Sequencing entails determination of the positions of sulfation and uronic acid epimerization for each residue of a given molecule. The $m / z$ of the precursor ion establishes the composition with respect to the number of residues (HexA and GlcN), acetate and sulfate groups. Tandem mass spectrometric product ions resulting from a series of glycosidic bond cleavages define the masses of individual residues and thus determine number of sulfate and acetate groups on each. Cross-ring cleavages are useful for determining the hydroxyl groups that carry a sulfate group on a given residue. Because the nascent chains are synthesized as polymers of repeating disaccharide units, the linkages of which do not change during subsequent enzymatic modifications to form the mature, sulfated and epimerized chains, linkage and anomericity are not analytical variables. It is very important to develop tandem mass spectrometric methods which maximize the abundances of structurally useful ions from glycosidic bond or cross-ring cleavages while minimizing those from competing processes such as fragmentation that results in loss of sulfate groups.

Previous work from this laboratory demonstrated that the product ion pattern and information content of HLGAG tandem mass spectra strongly depend on the charge state of the precursor ion. For low negative charge states, in which some of the sulfate groups are protonated, abundant losses of $\mathrm{SO}_{3}$ dominate the product ion profiles. For higher negative charge states, wherein more than half the sulfate groups are charged, abundant glycosidic bond cleavages are produced. It is likely that charge-charge repulsions create bond strain and increase the abundances of ions resulting from cleavage of glycosidic bonds relative to those from $\mathrm{SO}_{3}$ losses. Although these results showed that subsequent stages of $\mathrm{CID}$ on $\left[\mathrm{M}-\mathrm{SO}_{3}-\mathrm{nH}\right]^{\mathrm{n}-}$ ions result in increased yield of glycosidic bond cleavage ions, the value of multistage MS has not yet been thoroughly investigated.

For practical sequencing purposes, it is desirable to maximize the abundances of ions resulting from glycosidic bond and cross-ring cleavages while minimizing those from competing processes. For this purpose, it is essential to understand the influence of precursor ion charge states on the formation of structurally useful product ions for highly sulfated carbohydrates. In a previous contribution, we demonstrated that the extent of $\mathrm{SO}_{3}$ losses diminishes as the absolute value of the negative charge state of the HLGAG ions increases [23]. The detailed fragmentation pathways for these ions, however, were not described with respect to glycosidic bond, cross-ring, and competing cleavage processes. This information is necessary for a complete understanding of the CID fragmentation of HLGAG ions, and will enable the development of useful mass spectrometric sequencing. In the present work, solvent conditions are described that allow precise manipulation of HLGAG ion charge states. Next, the fragmentation pathways of highly charged ions generated from five HLGAG structures are described, and it is shown in detail how the formation of glycosidic bond cleavage ions competes with other fragmentation pathways. The implications of these multiple fragmentation channels on practical sequencing of HLGAGs are discussed in detail.

\section{Experimental}

\section{Materials}

HPLC grade methanol, water, isopropanol and ammonium hydroxide were purchased from Burdick and Jackson (Muskegon, MI). Synthetic heparin-like glycosaminoglycans, Structures B-D, were synthesized in the laboratory of P. Seeberger (MIT, Cambridge, MA) [24]. Synthetic heparin-like glycosaminoglycans A and E were provided kindly by Sanofi-Synthelabo (Toulouse, France).

\section{Quadrupole Ion Trap (QIT) Mass Spectrometry}

Nanospray mass spectra were acquired using a Bruker Daltonics (Billerica, MA) Esquire 3000 instrument equipped with a Picoview Nano-electrospray source. Ionization was achieved using a spray voltage of $750 \mathrm{~V}$, ion drying temperature of $150{ }^{\circ} \mathrm{C}$, skimmer voltage of $-10.6 \mathrm{~V}$, and capillary exit offset of $-20.0 \mathrm{~V}$. Under these optimized conditions, ions were desolvated without inducing losses of $\mathrm{SO}_{3}$, so that deprotonated molecular ions were observed. The nanospray needle was positioned 1-2 $\mathrm{mm}$ away from the ion source orifice and the needle was positioned off-axis such that the spray cone was sampled at its outer edges. For optimal resolution, a scanning speed of $1650 \mathrm{~m} / \mathrm{z} \mathrm{sec}^{-1}$ was used and the target ion count was limited to 6000. HLGAG oligosaccharides were dissolved at a concentration of 1 $\mathrm{pmol} / \mu \mathrm{L}$ in the specified solvent compositions. For CID analysis, precursor ions were isolated in 1-3 u windows and excited in $1 \mathrm{u}$ windows. Collisional amplitude was adjusted so that fragment ions were produced without obliterating the precursor ion.

\section{Results and Discussion}

\section{ESI Conditions for Production of Highly Charged Ions from Sulfated Oligosaccharides}

HLGAG oligosaccharides may be analyzed by negative ESI-MS yielding abundant deprotonated ions and less abundant sodium, potassium, and ammonium adducts 

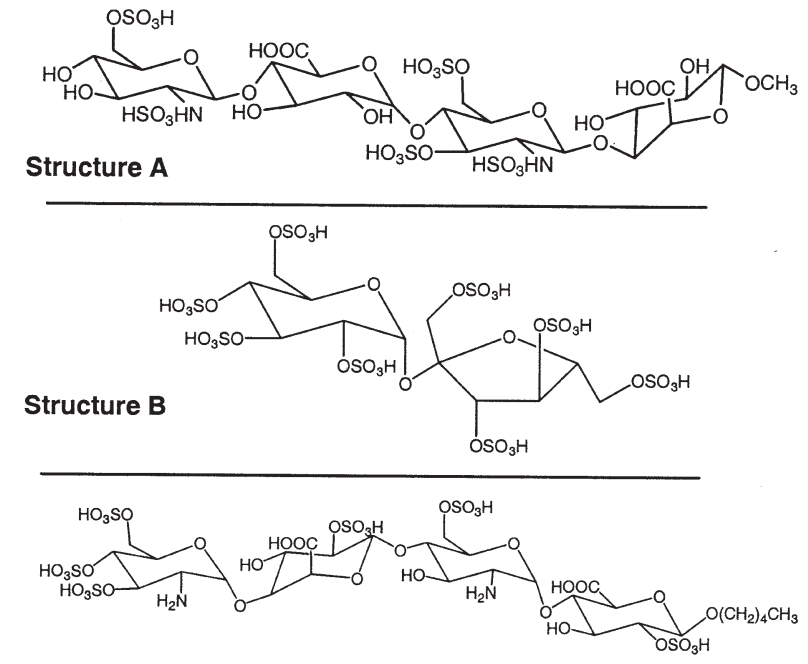

Structure C

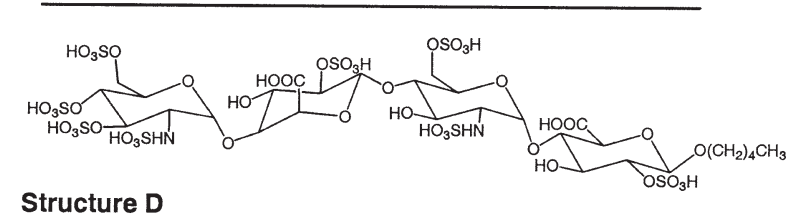

Structure D

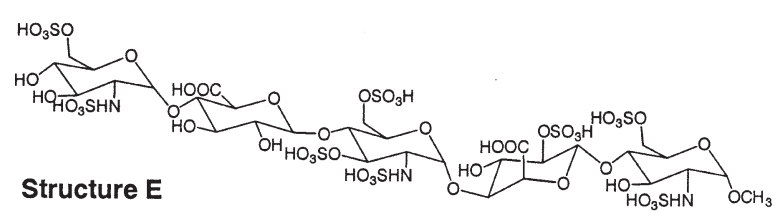

Scheme 1. Structures of HLGAGs studied in this work.

[10, 13-15]. Solvent conditions and skimmer voltages may be adjusted to minimize the spectral complexity that results from the occurrence of ions formed via loss(es) of $\mathrm{SO}_{3}$ in the ion source, to disfavor adduct formation and to control charge state formation. The goal of the first part of this study was to enhance the deprotonation and thereby produce a large proportion of highly charged precursor ions through the optimization of solvent conditions when analyzing highly sulfated carbohydrates by negative ion ESI-MS.

The synthetic pentasulfated HLGAG tetramer, Structure A in Scheme 1, was analyzed by negative ionization ESI under several solvent conditions. Figure 1 shows the negative ESI mass spectra of this structure, analyzed using identical source desolvation conditions dissolved in (a) 30\% methanol, $100 \mathrm{mM}$ ammonium acetate, $0.1 \%$ ammonium hydroxide, (b) $30 \%$ methanol, $0.1 \%$ ammonium hydroxide, (c) $80 \%$ methanol, $0.1 \%$ ammonium hydroxide, (d) $80 \%$ acetonitrile, $0.1 \%$ ammonium hydroxide, (e) $5 \%$ isopropanol, $0.1 \%$ ammonium hydroxide, and (f) $20 \%$ isopropanol, $0.1 \%$ ammonium hydroxide. Ions with 5-, 4-, 3- and 2-charge states are observed, corresponding to deprotonation of five, four, three, and two acidic groups, respectively, the abundances of which vary in different solvent conditions.

When analyzed in 30\% methanol, $100 \mathrm{mM}$ ammo- nium acetate, $0.1 \%$ ammonium hydroxide (a), the 3 - ion is observed with the highest abundance, followed by the 2- ion. Abundant ions corresponding to sodium adducted species are observed for the 2- charge state. When analyzed in 30\% methanol, $0.1 \%$ ammonium hydroxide (b), charge states are observed in the order of abundance $4->3->5-\gg 2$ - Sodium adducted ions are observed, particularly for the 2- charge state. When analyzed in $80 \%$ methanol, $0.1 \%$ ammonium hydroxide (c), the order of charge state abundance observed is $4->5->3->2-$, with an increase in the abundance of sodium-adducted ions. Analysis using $80 \%$ acetonitrile, $0.1 \%$ ammonium hydroxide yielded charge states in order of abundance 4->5->3- $\gg 2$ - (d), with ions formed from sodium adduction in lower abundances relative to those observed in (c). The 5\% isopropanol, $0.1 \%$ ammonium hydroxide condition (e) resulted in charge state abundances of 5-, 4- $\gg 3$-. Analysis with $20 \%$ isopropanol, $0.1 \%$ ammonium hydroxide (f) yielded results similar to that observed using $80 \%$ acetonitrile, $0.1 \%$ ammonium hydroxide, condition (c), above.

The abundances of the charge states observed under each condition are dictated by factors including the molecular conformation of the ion in solution ${ }^{14}$, instrumental ion source conditions [15], $\mathrm{pH}$ [16], solvent polarity [17], and solvent volatility [18, 19]. In these experiments the $\mathrm{pH}$ and instrument operating conditions were held constant. The abundances of highly charged ions were found to increase as the volatility of the solvent decreased, with optimal results (maximum charge states) observed when samples were analyzed in $5 \%$ isopropanol, $0.1 \%$ ammonium hydroxide. A possible explanation is that low-volatility droplets have greater surface tension and are therefore able to bear a greater amount of charge than are those with higher volatility [18].

The results show that the charge states are highest and the ions displaying sodium adduction lowest in abundances when the solvent is 5\% isopropanol, $0.1 \%$ ammonium hydroxide. Under no solvent conditions were species observed to have undergone loss of $\mathrm{SO}_{3}$ as a result of in-source fragmentation. Thus, it has been demonstrated that highly deprotonated HLGAG ions can be formed in 5\% isopropanol, $0.1 \%$ ammonium hydroxide and desolvated to yield more abundant highly charged species, with minimal sodium adduction and complete retention of sulfate groups.

The remaining four sulfated oligosaccharides shown in Scheme 1 were analyzed using negative ESI-MS analysis to further demonstrate the usefulness of $5 \%$ isopropanol, $0.1 \%$ ammonium hydroxide for producing abundant ions with high charge state and with a low occurrence of adduction. The mass spectra in Figure 2 show abundant ions resulting from deprotonation of sulfate groups and sodium adduct ions in low abundance. For oligosaccharide B, sucrose octasulfate, the most abundant charge states observed are 4- $>5$-. Interestingly, these ions exist predominantly as ammonium adduct ions, $\left[\mathrm{M}-\mathrm{nH}+\mathrm{NH}_{4}\right]^{(\mathrm{n}-1)-}$. To date, sucrose 

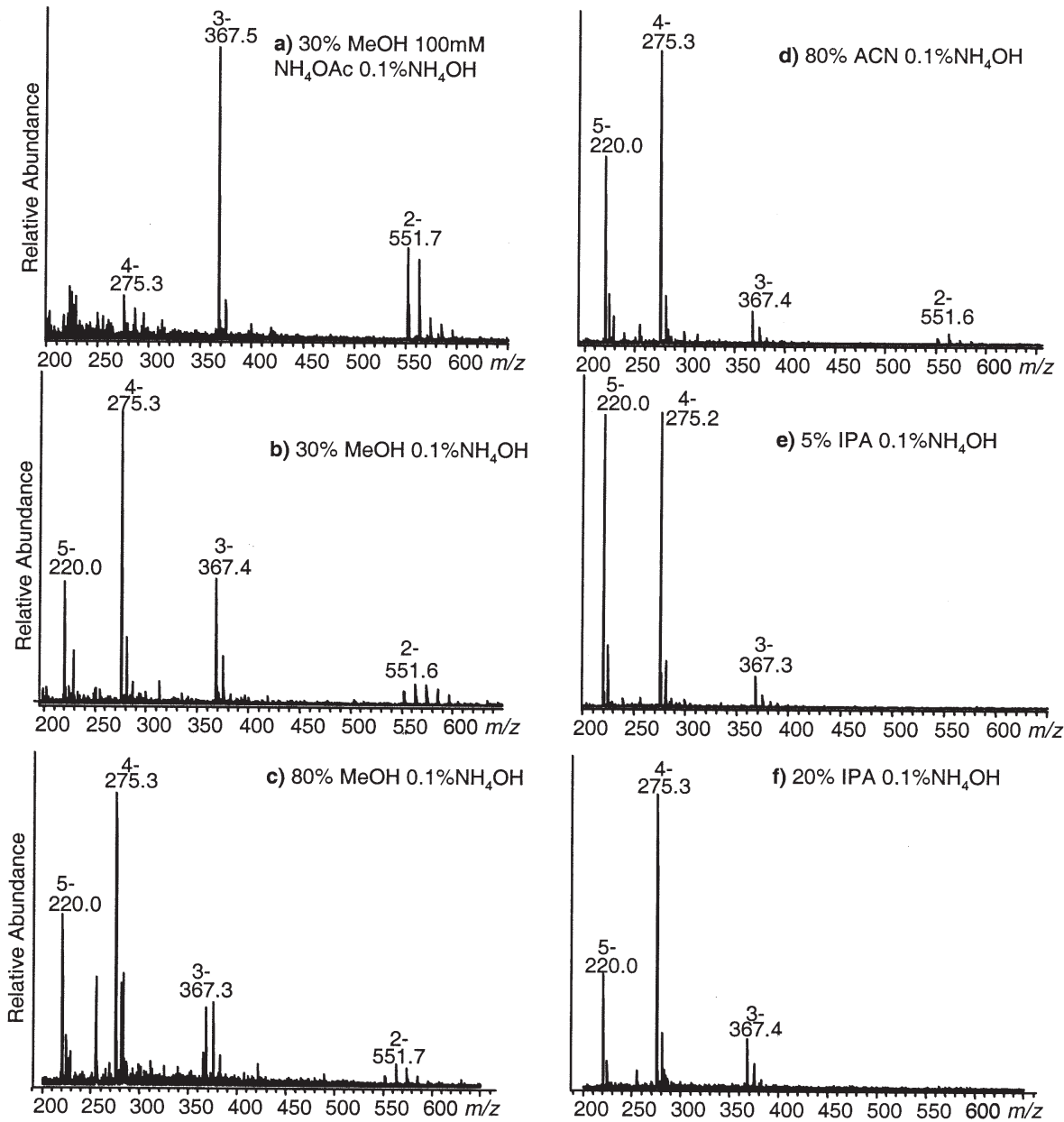

$200250300350400450500550600 \mathrm{~m} / \mathrm{z}$

Figure 1. Negative ESI mass spectra of Structure A, a pentasulfated tetrasaccharide, acquired using a QIT instrument with varying solvent conditions. Abbreviations: IPA, isopropyl alcohol; ACN, acetonitrile; $\mathrm{MeOH}$, methanol.

octasulfate has been successfully analyzed by positive and negative ESI only in the presence of quaternary ammonium ion pairing agents and was then found to produce abundant singly charged ions [25]. The results shown here demonstrate that intact sucrose octasulfate ions can be observed in the negative mode without the use of ion pairing agents.

The mass spectrum of Structure C, a hexasulfated tetrasaccharide containing no $\mathrm{N}$-sulfation, exhibits charge states of the order 5- $>4$ - where $[\mathrm{M}-\mathrm{nH}]^{\mathrm{n}-}$ ions are observed. Analysis of Structure D, an octasulfated tetrasaccharide, produced abundant ions of charge state 6->5->4-, all as $[\mathrm{M}-\mathrm{nH}]^{\mathrm{n}-}$ ions. Structure E, an octasulfated pentasaccharide, yielded charge states of the order 6->5- as $[\mathrm{M}-\mathrm{nH}]^{\mathrm{n}-}$ ions. In contrast to the results observed when ion pairing agents were used, ions formed with this method exhibited a higher degree of sulfate deprotonation and adduct formation was suppressed. With the exception of the spectrum obtained for Structure B, the most abundant ion was that of the highest observed charge state, although ions corresponding to complete deprotonation of sulfate groups were observed only for Structure A. These results are consistent with the conclusion that likecharge repulsions limit the abundances of high charge state ions during the ESI process. Losses of $\mathrm{SO}_{3}$ were not observed in the precursor ion profiles of these HLGAG structures.

HLGAGs have been paired with basic peptides [14, $15,20]$ and ammonium counterions [10, 25, 26] to facilitate mass spectrometric analysis. Ion pairing reduces the abundances of ions that show sodium adduction, prevents losses of $\mathrm{SO}_{3}$, yields one dominant charge state, and thereby produces a simple mass spectrum [21]. It is not possible, however, to utilize CID experiments for oligosaccharide sequencing of HLGAG-basic peptide ion pairs, because the spectra are recorded in the positive mode and the charge is carried on the peptide. Although it is possible to ionize ammonium cation-HLGAG pairs in the negative mode, isolation and fragmentation of the precursor ions results in an abundant product ion formation primarily by loss of the pairing group. 


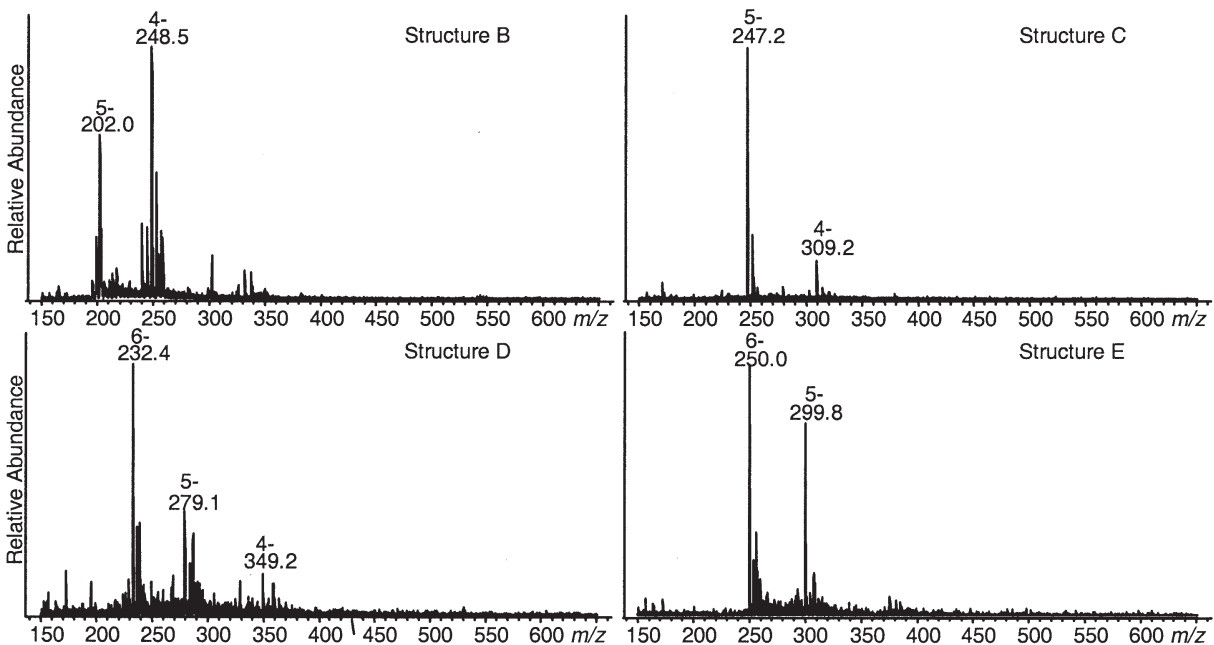

Figure 2. Negative ion electrospray mass spectra of HLGAGs acquired with a QIT instrument using solutions of $5 \%$ isopropanol, $0.1 \%$ ammonium hydroxide.

\section{Tandem Mass Spectrometry of Sucrose Octasulfate}

The CID product ion mass spectrum of the sucrose octasulfate (SOS, Structure B) $\left[\mathrm{M}\left(\mathrm{NH}_{4}\right)-4 \mathrm{H}\right]^{4-}$ ion $(\mathrm{m} / \mathrm{z} 248.5$, calculated value 248.69), is shown in Figure 3. The most abundant ion is the $[\mathrm{M}(\mathrm{Na})-4 \mathrm{H}]^{4-}(\mathrm{m} / \mathrm{z}$ 249.6, calculated value 249.93) which is isolated along with the $\left[\mathrm{M}\left(\mathrm{NH}_{4}\right)-4 \mathrm{H}\right]^{4-}$ ion and does not fragment under the conditions used. The inset shows the precursor ion region acquired with $0 \mathrm{~V}$ (top) and $0.23 \mathrm{~V}$ (bottom) collision amplitude and demonstrates that the ions are clearly resolved. A product ion observed at $\mathrm{m} / \mathrm{z}$ 244.2 , a $[\mathrm{M}-4 \mathrm{H}]^{4-}$ ion (calculated $\mathrm{m} / z$ 244.43), corresponds to the facile loss of ammonia, and demonstrates the weak interaction of the ammonium counter ion with the sulfate group, a phenomenon that has been previously observed [27]. Ions corresponding to glycosidic bond cleavages with losses of $\mathrm{SO}_{3},(\mathrm{~m} / \mathrm{z} 208.7, z=2$, calculated value 208.96), equivalents of $\mathrm{H}_{2} \mathrm{SO}_{4}(\mathrm{~m} / \mathrm{z}$ 400.6, $z=1$, calculated value 400.92$)$ and $2\left(\mathrm{H}_{2} \mathrm{SO}_{4}\right)(\mathrm{m} / \mathrm{z}$ 302.6, $z=1$, calculated value 302.95) are observed. This product ion profile is consistent with the existence of two populations of precursor ions, one of which has two charges on each residue and undergoes loss of $\mathrm{SO}_{3}$, as would be expected since half of the sulfate groups remain protonated. This population may also undergo loss of an equivalent of $\mathrm{H}_{2} \mathrm{SO}_{4}$ to form a singly charged ion. The loss of an equivalent of $\mathrm{H}_{2} \mathrm{SO}_{4}$ accompanies a loss of charge from the precursor ion. Because the mechanism behind this process is not clear, the loss of the equivalent of $\mathrm{H}_{2} \mathrm{SO}_{4}$ is understood to include reduction in ion charge in this work. Another population undergoes loss of two equivalents of $\left(\mathrm{H}_{2} \mathrm{SO}_{4}\right)$ to form a singly charged ion, indicating that the precursor ion exists with three charges on one residue. As will be shown below, losses of $\mathrm{H}_{2} \mathrm{SO}_{4}$ appears to occur for ion populations with a high degree of charge-charge repulsions on proximal sulfate groups.

\section{Tandem Mass Spectrometry of HLGAGs}

The CID product ion mass spectrum of the $[\mathrm{M}-5 \mathrm{H}]^{5-}$ ion generated from Structure C, a hexasulfated tetrasaccharide containing no $\mathrm{N}$-sulfation, results in a complete series of $\mathrm{Y}_{\mathrm{n}}$ ions, in addition to an $\left[\mathrm{M}-\mathrm{SO}_{3}\right]^{5-}$ ion (see Figure 4). Ions corresponding to $\mathrm{B}_{3}-\mathrm{SO}_{3}, \mathrm{~B}_{3}-2\left(\mathrm{SO}_{3}\right)$ and $\mathrm{B}_{1}-\mathrm{SO}_{3}$ are observed at very low abundances (see Table 1a). Isolation and $\mathrm{MS}^{3}$ fragmentation of $\mathrm{Y}_{3}{ }^{3-}$ results in the formation of $\mathrm{Y}_{2}{ }^{2-}, \mathrm{Y}_{1}{ }^{1-/ 2-}, \mathrm{Y}_{3} / \mathrm{C}_{3}{ }^{2-}, \mathrm{Y}_{3} /$ $\mathrm{B}_{3}{ }^{2-}$, and $\mathrm{Y}_{3} / \mathrm{B}_{4}{ }^{3-}$ ions, increasing the number of glycosidic bonds for which fragment ions are detected.

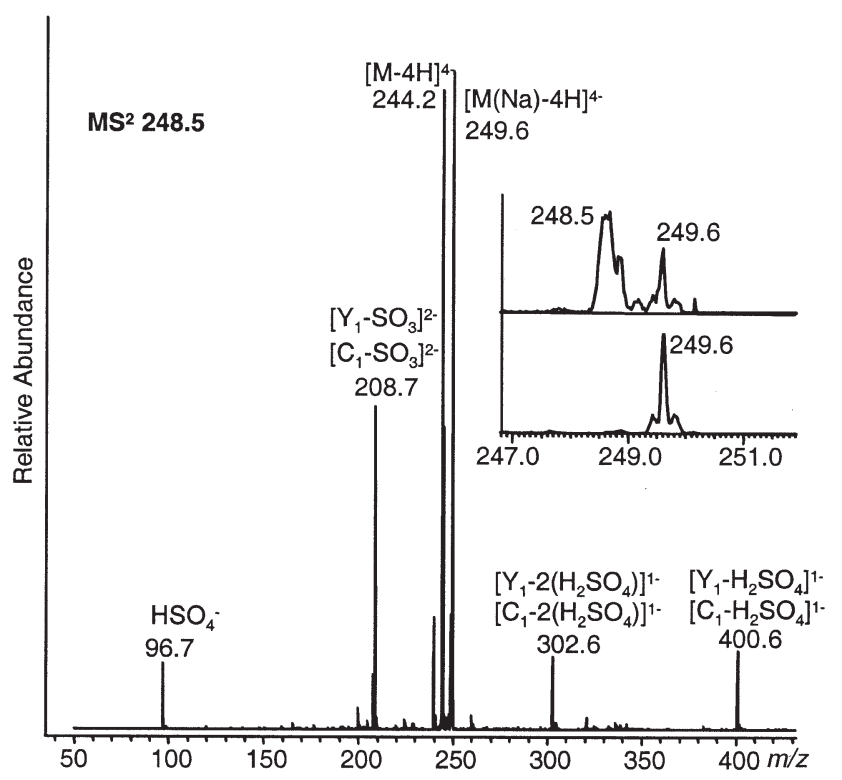

Figure 3. CID product ion mass spectrum (fragmentation window $3.0 \mathrm{u}$, collision amplitude $0.23 \mathrm{~V}$ ) of the $\left[\mathrm{M}-5 \mathrm{H}+\mathrm{NH}_{4}\right]^{4-}$ ion of sucrose octasulfate. The inset shows the precursor ion region with $0 \mathrm{~V}$ (top) and $0.23 \mathrm{~V}$ (bottom) collision amplitude. 


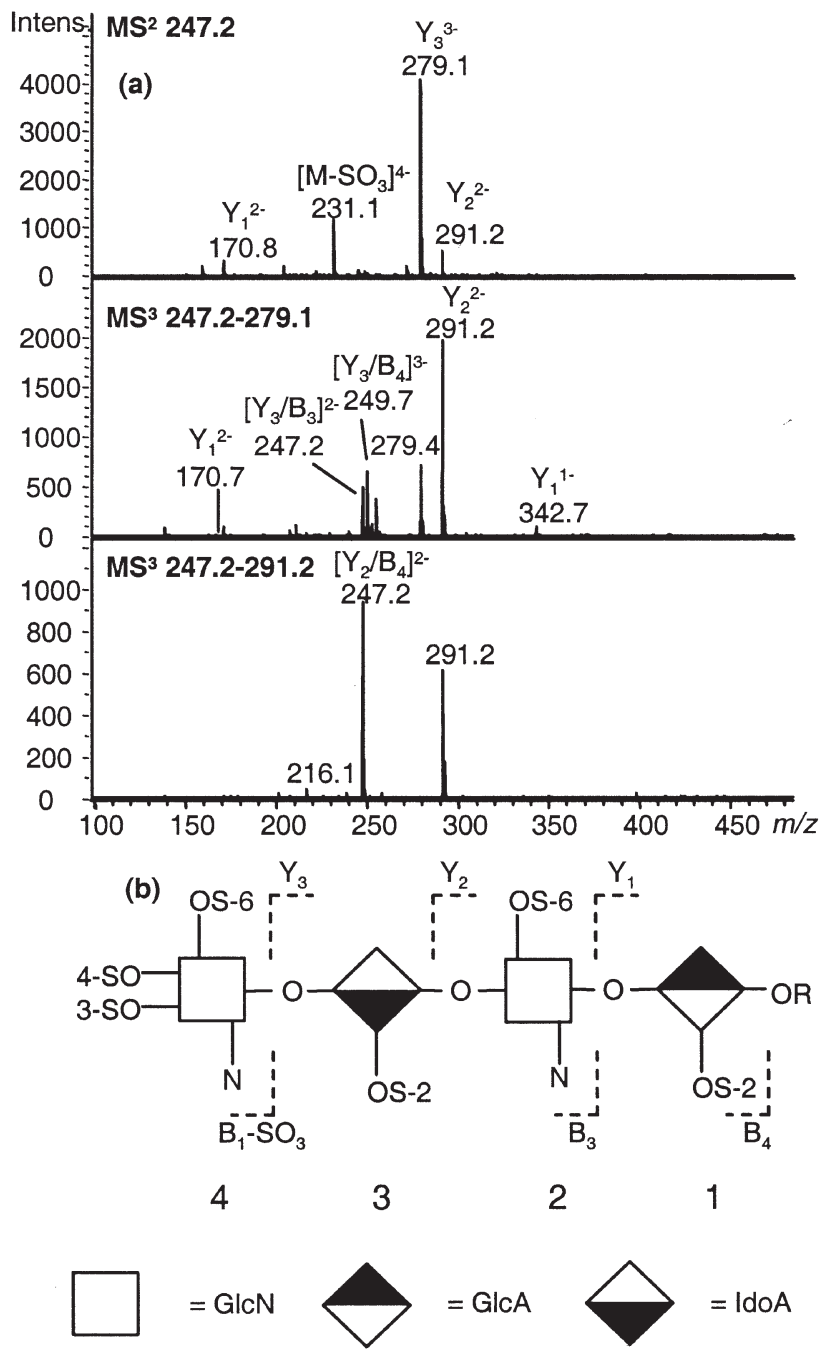

$\mathrm{OS}=\mathrm{OSO}_{3} \mathrm{H}$ position indicated by the numeral, $\mathrm{N}=\mathrm{NH}_{2}, \mathrm{NS}=\mathrm{NHSO}_{3} \mathrm{H}$.

(c)

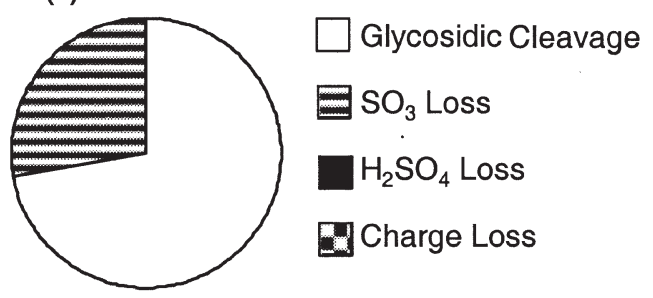

Figure 4. (a) $\mathrm{MS}^{2}$ (top, fragmentation window $3.0 \mathrm{u}$, collision amplitude $0.30 \mathrm{~V}$ ) of the $[\mathrm{M}-5 \mathrm{H}]^{5-}$ ion of Structure $\mathrm{C}$ followed by $\mathrm{MS}^{3}$ of the two most abundant product ions formed by glycosidic bond cleavage observed at $\mathrm{m} / \mathrm{z} 279.1$ (middle, $2.0 \mathrm{u}, 0.28 \mathrm{~V}$ ) and $\mathrm{m} / \mathrm{z} 291.2$ (bottom, $2.0 \mathrm{u}, 0.29 \mathrm{~V}$ ). Results are summarized in Table 1a, b, and c. (b) Block diagram of Structure A indicating the most abundant fragment ions. The symbols are defined and $\mathrm{R}=$ $\left(\mathrm{CH}_{2}\right)_{4} \mathrm{CH}_{3}$. (c) Pie chart showing the percent distribution of the total product ion abundances in the indicated fragmentation types.

Subsequent $\mathrm{MS}^{4}$ fragmentation of the $\mathrm{Y}_{2}{ }^{2-}$ ion $(\mathrm{m} / \mathrm{z}$ 291.2) results in the formation of $\mathrm{a}_{2} / \mathrm{B}_{4}{ }^{2-}$ ion.

This series of spectra were acquired by isolating and fragmenting the ions having the highest abundances in
Table 1. Product ions obtained from CID of Structure C, see Figure 4.

\begin{tabular}{|c|c|c|c|c|}
\hline Obs. $\mathrm{m} / \mathrm{z}$ & $z$ & Abund. & Ion & Calc. $m / z$ \\
\hline \multicolumn{5}{|c|}{ (a) $\mathrm{MS}^{2} 247.2$} \\
\hline 159.2 & 2 & 214 & $\mathrm{~B}_{1}-\mathrm{SO}_{3}$ & 159.48 \\
\hline 170.8 & 2 & 316 & $Y_{1}$ & 171.03 \\
\hline 291.2 & 2 & 126 & $\mathrm{Y}_{2}$ & 291.54 \\
\hline 244.7 & 3 & 123 & $\mathrm{~B}_{3}-2 \mathrm{SO}_{3}$ & 245.01 \\
\hline 271.4 & 3 & 203 & $\mathrm{~B}_{3}-\mathrm{SO}_{3}$ & 271.66 \\
\hline 279.1 & 3 & 4021 & $Y_{3}$ & 279.36 \\
\hline 231.1 & 5 & 1165 & $\mathrm{M}-\mathrm{SO}_{3}$ & 231.41 \\
\hline \multicolumn{5}{|c|}{ (b) $\mathrm{MS}^{3}$ 247.2-279.1 } \\
\hline 170.7 & 2 & 88 & $Y_{1}$ & 171.03 \\
\hline 342.7 & 1 & 92 & $Y_{1}$ & 343.07 \\
\hline 247.2 & 2 & 490 & $\mathrm{Y}_{3} / \mathrm{B}_{3}$ & 247.50 \\
\hline 254.7 & 1 & 372 & $\mathrm{Y}_{3} / \mathrm{B}_{2}$ & 254.98 \\
\hline 291.2 & 2 & 1928 & $Y_{2}$ & 291.54 \\
\hline 249.7 & 3 & 635 & $\mathrm{Y}_{3} / \mathrm{B}_{4}$ & 249.99 \\
\hline \multicolumn{5}{|c|}{ (c) $\mathrm{MS}^{4}$ 247.2-279.1-291.2 } \\
\hline 216.2 & 2 & 37 & $\left(\mathrm{Y}_{2} / \mathrm{B}_{4}\right)-\mathrm{H}_{2} \mathrm{O}-\mathrm{CO}_{2}$ & 216.50 \\
\hline 247.2 & 2 & 920 & $\mathrm{Y}_{2} / \mathrm{B}_{4}$ & 247.50 \\
\hline
\end{tabular}

the $\mathrm{MS}^{2}$ and $\mathrm{MS}^{3}$ stages, respectively. As shown in Figure $4 \mathrm{~b}$, if the compound were unknown one sulfate group could not be definitively placed, due to the absence of an intact $B_{1}$ ion. In effect, the data would describe most of the structure but would leave the location of one sulfate group ambiguous. Figure 4c shows the distribution of total product ion abundance for the $\mathrm{MS}^{2}$ stage in pie chart form. Glycosidic bond product ions account for $72 \%$ of the total ion abundance, with the remainder accounted for by loss of $\mathrm{SO}_{3}$ from the precursor ion and glycosidic bond product ions as shown in Table 1.

The CID product ion mass spectrum of the [M $5 \mathrm{H}]^{5-}$ ion generated from structure $\mathrm{A}$ is shown in Figure 5a; this ion corresponds to one charge per sulfate group in this pentasulfated tetramer. As shown in Figure $5 \mathrm{~b}$ and Table $2 \mathrm{a}$, abundant ions corresponding to $\mathrm{Y}_{1}{ }^{1-}$ and $\mathrm{C}_{2}{ }^{2-}$ are observed, as well as $\mathrm{B}_{2}{ }^{2-}$ in lower abundance. The most abundant product ion corresponds to $\left[\mathrm{B}_{3}-\mathrm{H}_{2} \mathrm{SO}_{4}-\mathrm{SO}_{3}\right]^{3-}$. It is likely that a population of precursor ions is formed in which four charges are distributed among residues $2-4$ and one is located on residue 1 . Formation of the $\mathrm{B}_{3}$ ion thus gives rise to charge reduction through the concurrent loss of $\mathrm{H}_{2} \mathrm{SO}_{4}$. The loss of $\mathrm{SO}_{3}$ has been observed previously to accompany $\mathrm{B}_{\mathrm{n}}$ cleavage adjacent to GlcNS3S6S residues [23] and this process occurs here. It appears that the placement of all five charges on sulfate groups is energetically disfavored due to like-charge repulsions. It also appears that the existence of four charges on residues 2-4 places sufficient strain on the sulfate groups to allow loss of equivalents of $\mathrm{H}_{2} \mathrm{SO}_{4}$ with charge reduction to compete favorably with glycosidic bond cleavages.

In order to obtain complete information regarding the sulfation pattern, it is essential that the abundances of product ions formed without fragmentation to sul- 


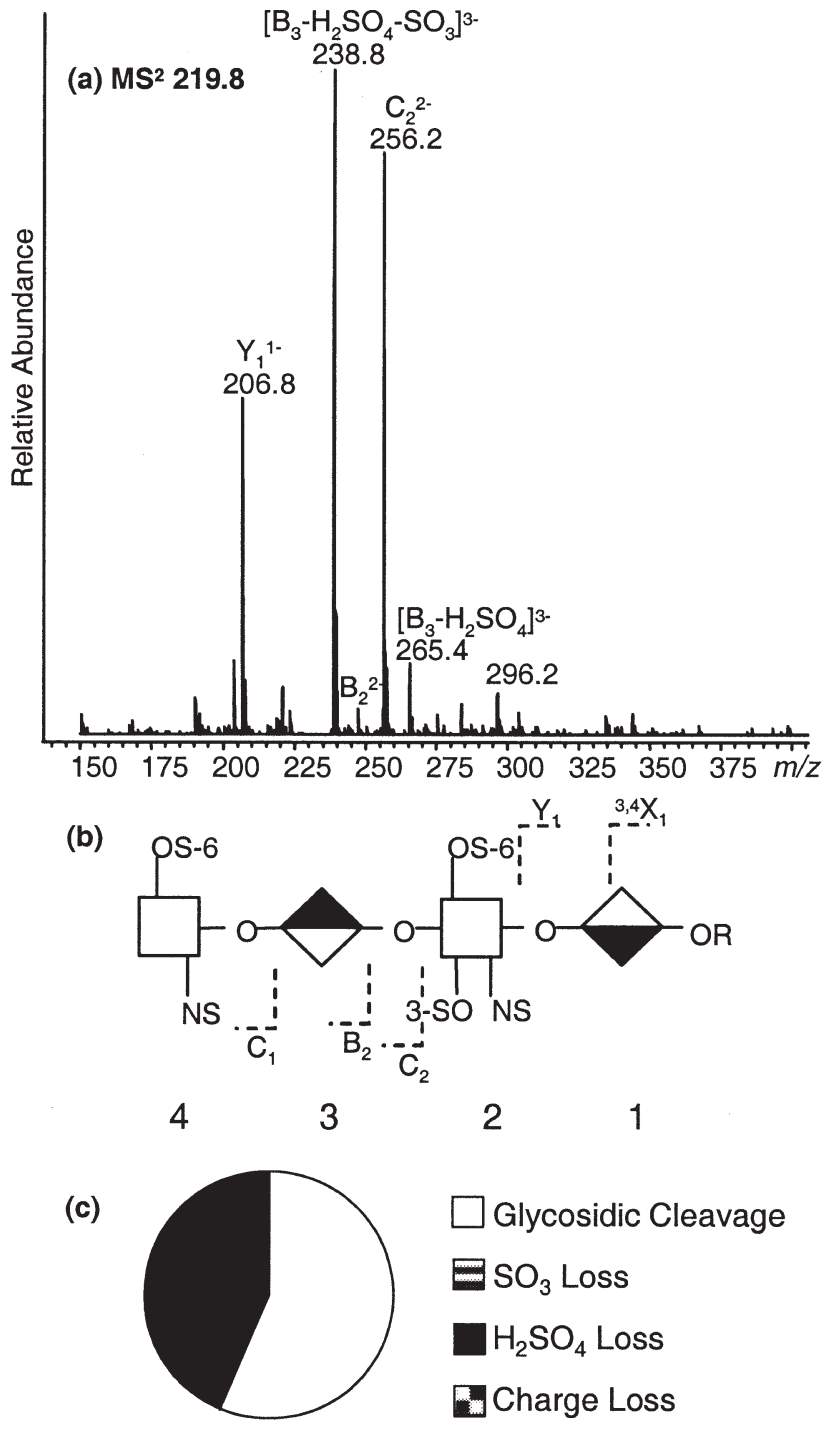

Figure 5. $\left(\mathrm{aMS}^{2}\right.$ of the $[\mathrm{M}-5 \mathrm{H}]^{5-}$ ion of Structure $\mathrm{A},(\mathbf{b})$ block diagram of Structure A indicating the most abundant product ions. For symbol definitions see Figure 4. (c) Pie chart showing the percent distribution of the total product ion abundances in the indicated fragmentation types.

fate groups be maximized Figure $5 \mathrm{c}$ shows the distribution of product ions for the $\mathrm{MS}^{2}$ stage of Structure A, $[\mathrm{M}-5 \mathrm{H}]^{5-}$ ion. Ions resulting from loss of equivalents of $\mathrm{H}_{2} \mathrm{SO}_{4}$ account for $44 \%$ of the total product ion abundance, including that of the $\left[\mathrm{B}_{3}-\mathrm{H}_{2} \mathrm{SO}_{4}-\mathrm{SO}_{3}\right]^{3}$ ion. These results are consistent with the conclusion that loss of an equivalent of $\mathrm{H}_{2} \mathrm{SO}_{4}$ occurs when a significant population of precursor ions contains charged groups on a single GlcN residue, as is the case for the $[\mathrm{M}-5 \mathrm{H}]^{5-}$ ion of Structure A. Although the $\mathrm{Y}_{1}$ and $\left[\mathrm{B}_{3}-\mathrm{H}_{2} \mathrm{SO}_{4}-\mathrm{SO}_{3}\right]^{3}$ ions observed in Figure 5a are produced from complementary cleavages of the same glycosidic bond, the locations of two sulfate groups cannot be defined. Despite the fact that subsequent stages of MS on these two product ions result in additional glycosidic bond cleavages $\left(\mathrm{B}_{2}, \mathrm{C}_{2} / \mathrm{Z}_{3}, \mathrm{C}_{2} / \mathrm{Y}_{3}\right)$
Table 2. Product ions generated by tandem mass spectrometric analysis of Structure A [M- $5 \mathrm{H}]^{5-}$ ion, see Figure 5, (a) $\mathrm{MS}^{2} \mathrm{~m} / \mathrm{z}$ 219.8, fragmentation window $3.0 \mathrm{u}$, collision amplitude $0.30 \mathrm{~V}$, (b) $\mathrm{MS}^{3} 219.8-238.8\left[\mathrm{~B}_{3}-\mathrm{H}_{2} \mathrm{SO}_{4}-\mathrm{SO}_{3}\right]^{3-} 3.0,0.3 \mathrm{~V}$, (c) $\mathrm{MS}^{4} 219.8-$ 238.8-256.2 $\left(\mathrm{C}_{2}{ }^{2-}\right)$ 3.0, $0.35 \mathrm{~V}$

\begin{tabular}{lrrll}
\hline \multicolumn{1}{c}{ Obs. $\mathrm{m} / z$} & $z$ Abund. & \multicolumn{1}{c}{ Ion } & Calc. $\mathrm{m} / \mathrm{z}$ \\
\hline \hline (a) $\mathrm{MS}^{2} 219.8$ & & & & \\
206.8 & 1 & 1925 & $\mathrm{Y}_{1}$ & 207.05 \\
238.8 & 3 & 3815 & $\mathrm{~B}_{3}-\mathrm{H}_{2} \mathrm{SO}_{4}-\mathrm{SO}_{3}$ & 239.00 \\
247.2 & 2 & 147 & $\mathrm{~B}_{2}$ & 247.50 \\
256.2 & 2 & 3334 & $\mathrm{C}_{2}$ & 256.50 \\
265.4 & 3 & 405 & $\mathrm{~B}_{3}-\mathrm{H}_{2} \mathrm{SO}_{4}$ & 265.65 \\
(b) $\mathrm{MS}^{3}$ & $219.8-238.8$ & & & \\
203.7 & 1 & 824 & $\left(\mathrm{~B}_{3}-\mathrm{H}_{2} \mathrm{SO}_{4}-\mathrm{SO}_{3}\right) / \mathrm{Z}_{2}$ & 203.99 \\
247.2 & 2 & 139 & $\mathrm{~B}_{2}$ & 247.50 \\
256.2 & 2 & 2471 & $\mathrm{C}_{2}$ & 256.50 \\
(c) $\mathrm{MS}^{4}$ & $219.8-238.8-256.2$ & & \\
168.2 & 2 & 11 & $\mathrm{C}_{1}$ & 168.49 \\
174.7 & 1 & 98 & $\mathrm{C}_{2} / \mathrm{Z}_{3}$ & 175.02 \\
192.7 & 1 & 229 & $\mathrm{C}_{2} / \mathrm{Y}_{3}$ & 193.03 \\
216.2 & 2 & 84 & $\mathrm{C}_{2}-\mathrm{SO}_{3}$ & 216.53 \\
239.7 & 1 & 223 & $\mathrm{~B}_{1}-\mathrm{SO}_{3}$ & 240.02 \\
247.2 & 2 & 85 & $\mathrm{C}_{2}-\mathrm{H}_{2} \mathrm{O}$ & 247.50 \\
257.7 & 1 & 164 & $\mathrm{C}_{1}-\mathrm{SO}_{3}$ & 258.03 \\
\hline
\end{tabular}

the ambiguity regarding two of the sulfate groups remains from the $\mathrm{MS}^{2}$ stage.

The CID product ion mass spectrum of the [M $6 \mathrm{H}]^{6-}$ ion of Structure E, an octasulfated pentasaccharide, reflects the formation of abundant glycosidic bond cleavage ions (see Figure 6a). Abundant ions corresponding to $B_{5}, B_{4}, C_{4}$ and $Y_{1}$ are observed and those produced from losses of equivalents of $\mathrm{H}_{2} \mathrm{SO}_{4}$ or $\mathrm{SO}_{3}$ have low abundances (see Table 3 and Figure 6c). One population of precursor ions fragments to produce a $\mathrm{B}_{4}{ }^{4-}$ ion, and a second, larger, produces $\mathrm{C}_{4}{ }^{5-}$. The ion at $m / z 300.1$, labeled $\left[\mathrm{M}-\left(\mathrm{H}^{-}\right)-6 \mathrm{H}\right]^{5-}$, corresponds to a precursor with a 5- charge, and appears to have been formed by loss of $\mathrm{H}^{-}$from the precursor ion. This process is discussed further below. The isolation and $\mathrm{MS}^{3}$ fragmentation of $\mathrm{B}_{4}{ }^{4-}$ results in the formation of three ions, $\left[\mathrm{C}_{4} / \mathrm{Y}_{4}\right]^{3-},\left[\mathrm{C}_{4} / \mathrm{Y}_{4}-\mathrm{SO}_{3}\right]^{3-}$, and $\left[\mathrm{B}_{4} / \mathrm{Y}_{4}\right]^{3-}$ (see Table $3 b$ ). The $\mathrm{MS}^{3}$ product ion mass spectrum generated from $\mathrm{C}_{4}{ }^{5-}$ results in a very complex product ion pattern (see Table 3c), with losses of $\mathrm{H}_{2} \mathrm{SO}_{4}$ and/or $\mathrm{SO}_{3}$ accompanying glycosidic bond cleavages. It appears that, while the $\mathrm{B}_{4}{ }^{4-}$ ion contains only two charges on the trisulfated $\mathrm{GlcN}$ residue, the $\mathrm{C}_{4}{ }^{5-}$ ion contains three such charges, under which conditions loss of $\mathrm{H}_{2} \mathrm{SO}_{4}$ competes favorably with glycosidic bond cleavages.

\section{Formation of Ions from Loss of Charge in Tandem Mass Spectra of a Highly Sulfated HLGAG Ion}

The CID product ion mass spectrum of the $[\mathrm{M}-6 \mathrm{H}]^{6-}$ ion generated from Structure D is shown in Figure 7. This structure is an octasulfated tetrasaccharide containing four sulfate groups on the non-reducing GlcN 

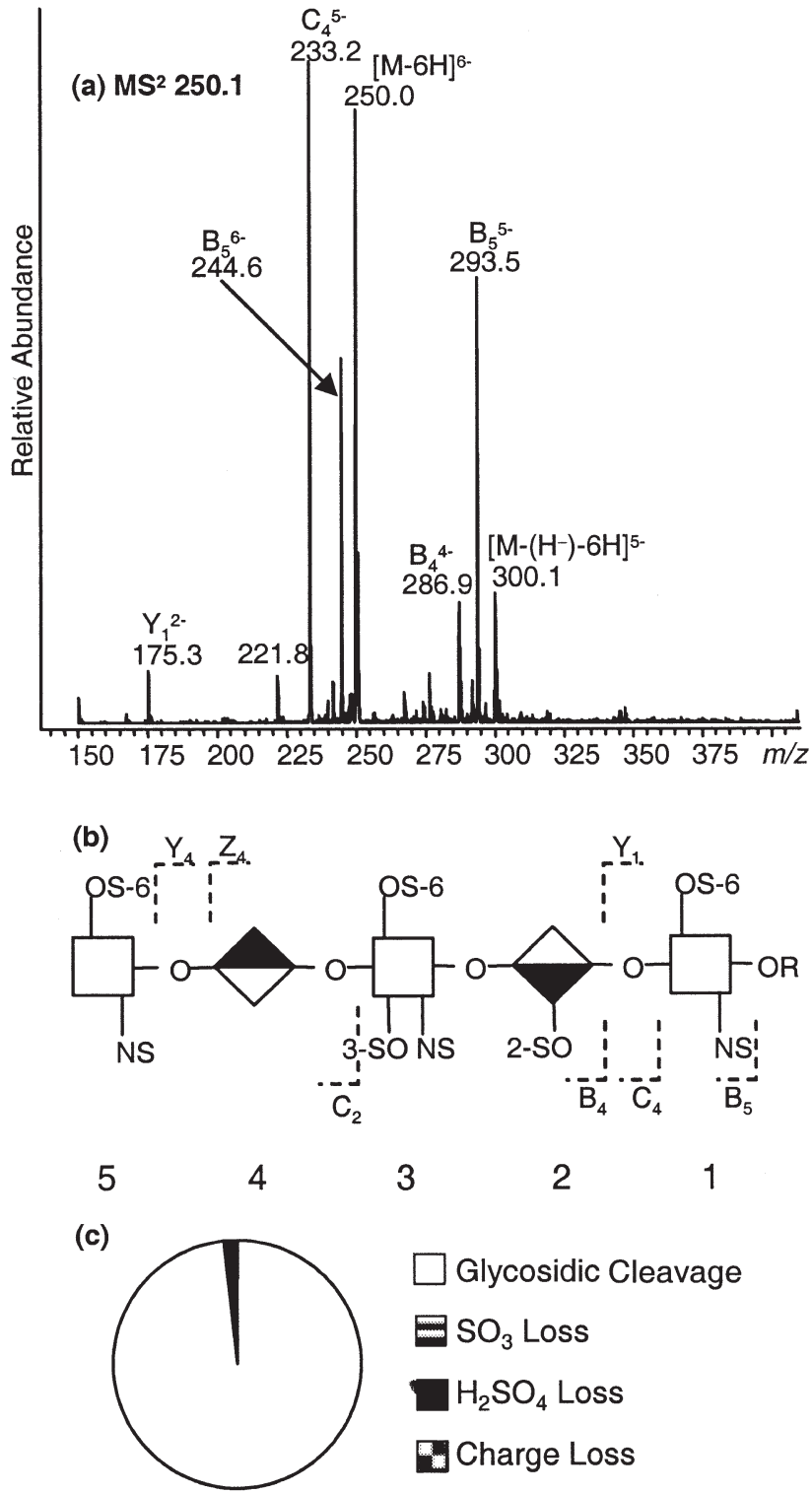

Figure 6. (a) $\mathrm{MS}^{2}$ of the $[\mathrm{M}-6 \mathrm{H}]^{6-}$ ion of Structure $\mathrm{E}$, (b) block diagram of Structure E indicating the most abundant product ions. For symbol definitions, see Figure 4. (c) Pie chart showing the percent distribution of the total product ion abundances in the indicated fragmentation types.

residue and the precursor ion shown in Figure 7a corresponds to $[\mathrm{M}-6 \mathrm{H}]^{6-}$. This ion fragments to produce very abundant ions from losses of charge from the precursor ion, and the $m / z$ values (see Table 4) are consistent with the formation of $\left[\mathrm{M}-\left(\mathrm{H}^{-}\right)-6 \mathrm{H}\right]^{5-}$ and $\left[\mathrm{M}-\left(2 \mathrm{H}^{-}\right)-6 \mathrm{H}\right]^{4-}$ species. Isolation and fragmentation of the ion at $\mathrm{m} / \mathrm{z} 279.1$ resulted in the formation of an ion at $m / z 349.0$, corresponding to [M - $\left(2 \mathrm{H}^{-}\right)$ $-6 \mathrm{H}]^{4-}$, as shown in Figure $7 \mathrm{~b}$. By contrast, $\mathrm{MS}^{2}$ isolation and fragmentation of the Structure D [M $5 \mathrm{H}]^{5-}$ ion results in the formation of an ion from loss of $\mathrm{SO}_{3}$ as well as those from glycosidic bond cleavages, see Figure 7c. The insets demonstrate that an ion at $\mathrm{m} / \mathrm{z}$ 279.0, $\left[\mathrm{M}-\left(\mathrm{H}^{-}\right)-6 \mathrm{H}\right]^{5-}$, is formed during $\mathrm{MS}^{2}$
Table 3. Product ions generated by tandem mass spectrometric analysis of Structure E, [M-6H] ${ }^{6-}$, see Figure 6, (a) $\mathrm{MS}^{2} 250.1$, fragmentation window $3.0 \mathrm{u}$, collision amplitude $0.20 \mathrm{~V}(\mathrm{~b}) \mathrm{MS}^{3}$ 250.1-287.0 $\mathrm{B}_{4}{ }^{4--}, 3.0 \mathrm{u}, 0.23 \mathrm{~V}$ (c) $250.1-233.2 \mathrm{C}_{4}{ }^{5-} 3.0 \mathrm{u}, 0.25 \mathrm{~V}$

\begin{tabular}{|c|c|c|c|c|}
\hline Obs. $m / z$ & \multicolumn{2}{|c|}{$z$ Abund. } & Ion & Calc. $m / z$ \\
\hline \multicolumn{5}{|c|}{ (a) $\mathrm{MS}^{2} 250.1$} \\
\hline 175.3 & 2 & 64 & $Y_{1}$ & 175.50 \\
\hline 276.4 & 3 & 60 & $\mathrm{~B}_{4} / \mathrm{Y}_{4}$ & 276.65 \\
\hline 267.2 & 4 & 36 & $\mathrm{~B}_{4}-\mathrm{SO}_{3}$ or $\mathrm{C}_{4}-\mathrm{H}_{2} \mathrm{SO}_{4}$ & 267.49 \\
\hline 286.9 & 4 & 146 & $\mathrm{~B}_{4}$ & 287.48 \\
\hline 291.7 & 4 & 51 & $\mathrm{C}_{4}$ & 291.98 \\
\hline 233.2 & 5 & 805 & $\mathrm{C}_{4}$ & 233.38 \\
\hline 241.6 & 6 & 33 & $\mathrm{~B}_{5}-\mathrm{H}_{2} \mathrm{O}$ & 241.81 \\
\hline 293.5 & 5 & 542 & $\mathrm{~B}_{5}$ & 293.98 \\
\hline 244.6 & 6 & 444 & $\mathrm{~B}_{5}$ & 244.81 \\
\hline 300.1 & 5 & 159 & {$\left[\mathrm{M}-\left(\mathrm{H}^{-}\right)-6 \mathrm{H}\right]$} & 300.18 \\
\hline \multicolumn{5}{|c|}{ (b) $\mathrm{MS}^{3} 250.1-287.0$} \\
\hline 255.7 & 3 & 24 & $\left(\mathrm{C}_{4} / \mathrm{Y}_{4}\right)-\mathrm{SO}_{3}$ & 256.00 \\
\hline 276.3 & 3 & 26 & $\mathrm{~B}_{4} / \mathrm{Y}_{4}$ & 276.65 \\
\hline 282.3 & 3 & 122 & $\mathrm{C}_{4} / \mathrm{Y}_{4}$ & 282.65 \\
\hline \multicolumn{5}{|c|}{ (c) $\mathrm{MS}^{3} 250.1-233.2$} \\
\hline 256.2 & 2 & 206 & $\mathrm{C}_{2}$ & 256.50 \\
\hline 223.7 & 3 & 96 & $\mathrm{C}_{3}-2 \mathrm{H}_{2} \mathrm{SO}_{4}-\mathrm{CO}_{2}$ & 224.34 \\
\hline 238.7 & 3 & 183 & $\mathrm{C}_{3}-2 \mathrm{H}_{2} \mathrm{SO}_{4}$ & 239.00 \\
\hline 244.7 & 3 & 68 & $\mathrm{C}_{3}-\mathrm{H}_{2} \mathrm{SO}_{4}-\mathrm{SO}_{3}$ & 245.00 \\
\hline 247.2 & 4 & 208 & $\mathrm{C}_{4}-\mathrm{H}_{2} \mathrm{SO}_{4}-\mathrm{SO}_{3}$ & 247.50 \\
\hline 267.2 & 4 & 207 & $\mathrm{C}_{4}-\mathrm{H}_{2} \mathrm{SO}_{4}$ & 267.50 \\
\hline 217.1 & 5 & 524 & $\mathrm{C}_{4}-\mathrm{SO}_{3}$ & 217.40 \\
\hline
\end{tabular}

fragmentation of the Structure E $[\mathrm{M}-6 \mathrm{H}]^{6-}$ ion but that one at $m / z 279.3,[\mathrm{M}-5 \mathrm{H}]^{5-}$, is observed by ESI MS (see Figure 2) and subjected to $\mathrm{MS}^{2}$ in Figure 7c. These $m / z$ values are consistent with the loss of $\mathrm{H}^{-}$ occurring during $\mathrm{MS}^{2}$ of $[\mathrm{M}-6 \mathrm{H}]^{6-}$ due to the high density of negative charge on this ion. To verify these conclusions, the measurements were repeated several times over different days and additional data were acquired using an instrument of the same geometry but made by a different manufacturer. In all cases, the results supported the same conclusions. The production of an ion from a similar loss of charge, consistent with $\mathrm{H}^{-}$loss from the precursor, is also observed for Structure E, see Figure 6.

Although ion-ion reactions in an ion trap mass spectrometer have been used to reduce charge for biomolecular ions [28-30], all ions in the cell in the present study are negatively charged and such reactions are therefore unlikely. Therefore, the observed reduction in charge state must be due to the elimination of a negative species from the precursor. Although the negative charge increases mathematically, the term charge reduction is used here because the absolute value of the charge on the product ion is lower than that of the precursor. The observations made here are, therefore, best explained by the ejection of a hydride ion from the highly charged precursor ion, forming otherwise intact precursor ions with diminished charge, but not equivalent to those produced from simple deprotonation. Fragmentation of the Structure D $\left[\mathrm{M}-\left(\mathrm{H}^{-}\right)-\right.$ $6 \mathrm{H}]^{5-}$ and $[\mathrm{M}-5 \mathrm{H}]^{5-}$ ions, respectively, produce 

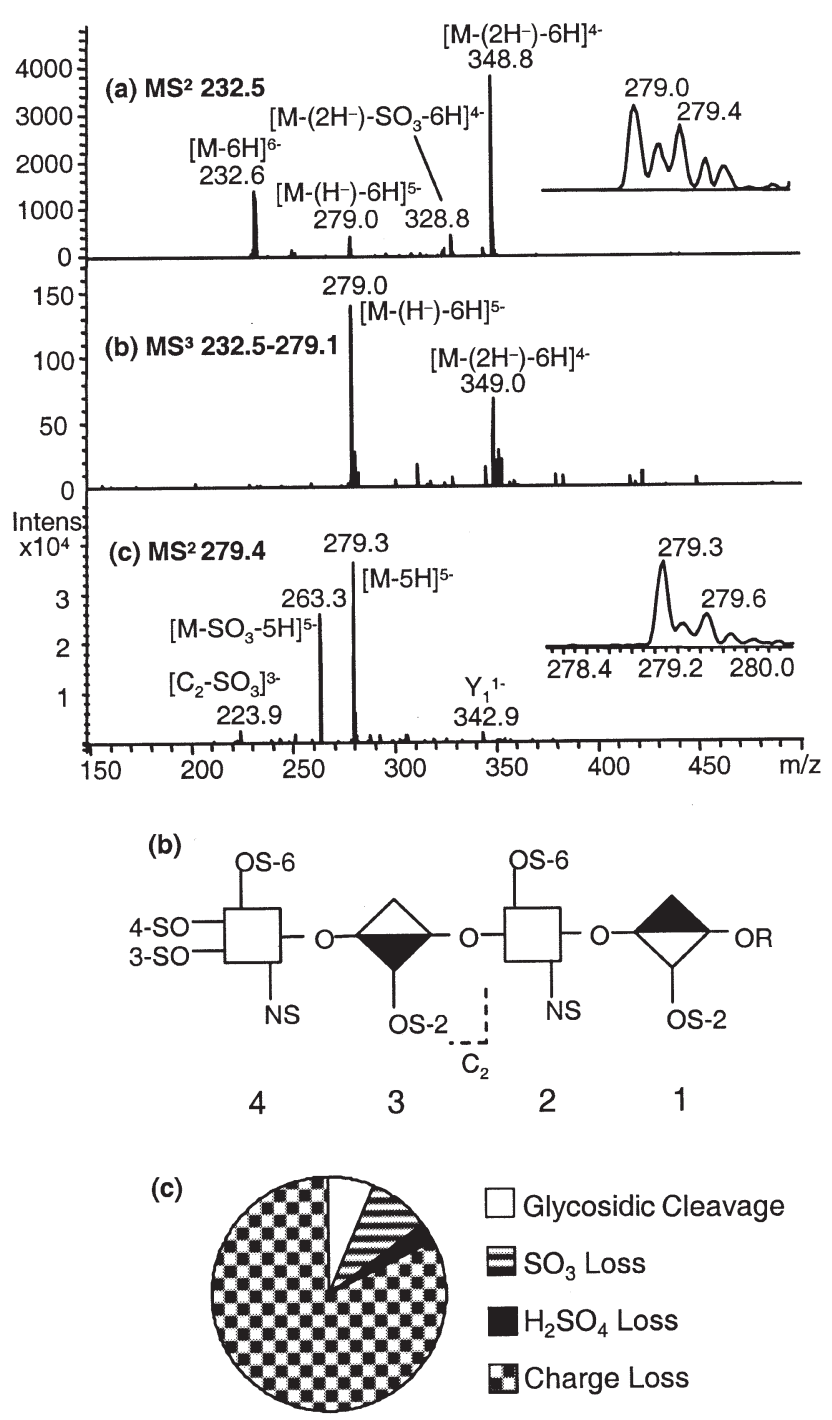

Figure 7. (a) $\mathrm{MS}^{2}$ of the $[\mathrm{M}-6 \mathrm{H}]^{6-}$ ion of Structure $\mathrm{D}$, (b) block diagram of Structure D indicating the most abundant product ions. For symbol definitions, see Figure 4. (c) Pie chart showing the percent distribution of the total product ion abundances in the indicated fragmentation types.

dramatically different patterns, see Figure 7. While fragmentation of the $[\mathrm{M}-5 \mathrm{H}]^{5-}$ ion $(\mathrm{m} / \mathrm{z} 279.4)$ results in a product ion pattern typical of other HLGAG ions (Figure $7 \mathrm{c}$ ), the $\left[\mathrm{M}-\left(\mathrm{H}^{-}\right)-6 \mathrm{H}\right]^{5-}$ ion $(\mathrm{m} / \mathrm{z} 279.1)$ is evidently quite unstable and fragments to lose another $\mathrm{H}^{-}$to form $\left[\mathrm{M}-\left(2 \mathrm{H}^{-}\right)-6 \mathrm{H}\right]^{4-}$ (Figure $7 \mathrm{~b}$ ). These observations indicate that the ions have different structures. Evidently, sufficient like-charge repulsion remains in the $\left[\mathrm{M}-\left(\mathrm{H}^{-}\right)-6 \mathrm{H}\right]^{5-}$ ion to make subsequent loss of $\mathrm{H}^{-}$favorable. This conclusion is supported by the high abundance of the $\left[\mathrm{M}-\left(2 \mathrm{H}^{-}\right)-\right.$ $6 \mathrm{H}]^{4-}$ in Figure 7a relative to that of the $\left[\mathrm{M}-\left(\mathrm{H}^{-}\right)-\right.$ $6 \mathrm{H}]^{5-}$ ion. Interestingly, the product ion profiles of the Structure D $[\mathrm{M}-4 \mathrm{H}]^{4-}$ and $\left[\mathrm{M}-\left(2 \mathrm{H}^{-}\right)-6 \mathrm{H}\right]^{4-}$ ions are the same, and reflect loss of $\mathrm{SO}_{3}$ from the precursor, consistent with both ions having relatively stable structures and behaving as expected for HLGAG ions with several protonated $\mathrm{SO}_{3}$ groups [23].
Table 4. Product ions generated by tandem mass spectrometric analysis of Structure D, see Figure 7, (a) $[\mathrm{M}-6 \mathrm{H}]^{6-} \mathrm{MS}^{2} 232.5$, fragmentation window $2.0 \mathrm{u}$, collision amplitude $0.15 \mathrm{~V}$, (b) [M$5 \mathrm{H}^{5-} \mathrm{MS}^{2}$ 279.4, $2.0 \mathrm{u}, 0.27 \mathrm{~V}$, (c) $\mathrm{MS}^{3}$ 232.5-279.1 $2.0 \mathrm{u}, 0.17 \mathrm{~V}$

\begin{tabular}{lrrll}
\hline Obs. $m / z$ & $z$ & Abund & \multicolumn{1}{c}{ Ion } & Calc. $m / z$ \\
\hline \hline (a) $\mathrm{MS}^{2} 232.5$ & & & & \\
232.6 & 6 & 1378 & {$[\mathrm{M}-6 \mathrm{H}]^{6-}$} & 232.65 \\
250.5 & 3 & 155 & $\mathrm{C}_{2}$ & 250.62 \\
279.0 & 5 & 428 & {$\left[\mathrm{M}-\left(\mathrm{H}^{-}\right)-6 \mathrm{H}\right]^{5-}$} & 279.18 \\
324.8 & 4 & 119 & {$\left[{\left.\mathrm{M}-\mathrm{H}_{2} \mathrm{SO}_{4}\right]^{4-}}_{324.99}\right.$} \\
328.8 & 4 & 449 & {$\left[\mathrm{M}-\mathrm{SO}_{3}-2\left(\mathrm{H}^{-}\right)-6 \mathrm{H}\right]^{4-}$} & 328.99 \\
344.3 & 4 & 164 & {$\left[\mathrm{Z}_{4}-2\left(\mathrm{H}^{-}\right)\right]^{4-}$} & 344.47 \\
348.8 & 4 & 3779 & {$\left[\mathrm{M}-2\left(\mathrm{H}^{-}\right)-6 \mathrm{H}\right]^{4-}$} & 348.97 \\
(b) $\mathrm{MS}^{2} 279.4$ & & & & \\
223.9 & 3 & 2521 & $\mathrm{C}_{2}-\mathrm{SO}_{3}$ & 223.97 \\
263.3 & 5 & 25854 & {$\left[\mathrm{M}-\mathrm{SO}_{3}-5 \mathrm{H}\right]^{5-}$} & 263.39 \\
279.3 & 5 & 15926 & {$[\mathrm{M}-5 \mathrm{H}]^{5-}$} & 279.38 \\
304.9 & 4 & 1315 & {$\left[\mathrm{Z}_{4}-2 \mathrm{SO}_{3}\right]$} & 305.00 \\
305.8 & 3 & 1466 & $\mathrm{Y}_{3}$ & 306.01 \\
342.9 & 1 & 1949 & $\mathrm{Y}_{1}$ & 343.07 \\
(c) $\mathrm{MS}^{3} 232.5-279.1$ & & & 348.97 \\
349.0 & 4 & 70 & {$\left[\mathrm{M}-2\left(\mathrm{H}^{-}\right)-6 \mathrm{H}\right] 4-$} & \\
\hline
\end{tabular}

\section{Conclusions}

Experiments were conducted using the optimized solvent conditions ( $5 \%$ isopropanol, $0.1 \%$ ammonium hydroxide), maximizing the charge state generated from the sulfated oligosaccharides and minimizing the extent of sodium adduction. Low energy CID tandem mass spectra were obtained for the highest charge state for five HLGAG structures. Four fragmentation processes compete during CID of HLGAG ions, (1) glycosidic bond cleavages (product ions from cross ring cleavages have been observed only with low relative abundances), (2) losses of $\mathrm{SO}_{3}$ from the precursor ion, observed in greatest abundances for lower charge states, (3) losses of equivalents of $\mathrm{H}_{2} \mathrm{SO}_{4}$ with charge reduction from the precursor ion, observed in greatest abundances for higher charges states, (4) loss of charge, in the form of $\mathrm{H}^{-}$, from the precursor ion, observed only for Structures D and E.

Glycosidic bond cleavages are facile when a proton or other cation is associated with the glycosidic oxygen atom, resulting in the generation of abundant product ions [31]. In the absence of such a cation, glycosidic bonds require considerably more energy before cleavage occurs, to the point that other fragmentation processes become energetically favorable. In cases where there are no mobile protons, such as for singly deprotonated ions produced from maltoheptaose, abundant cross ring cleavages occur and glycosidic bond cleavage ions are in low relative abundances [32]. Oligosaccharides cationized with large radius alkali metals require very large dissociation energies due to the fact that that the interactions with glycosidic oxygen atoms are weak, resulting in minimal destabilization of the associated bond [33]. Oligosaccharides cationized with a fixed metal at the 
reducing terminus produce abundant cross ring and less abundant glycosidic bond cleavage ions [34].

For HLGAG ions, the charge state is always lower than the number of mobile protons, and thus there is the potential for protons to be available for the destabilization of glycosidic bonds. Losses of $\mathrm{SO}_{3}$ occur when protons are associated with sulfate groups, and for this reason CID of high negative charge states has been investigated. For such charge states, charge-charge repulsion strains glycosidic bonds, making their cleavage compete favorably with $\mathrm{SO}_{3}$ losses. Losses of equivalents of $\mathrm{H}_{2} \mathrm{SO}_{4}$ appear to occur for ions with a charge density high enough that charge-charge repulsion strains the bond between ring carbon atoms and the sulfated oxygen atom. This strain evidently makes losses of equivalents of $\mathrm{H}_{2} \mathrm{SO}_{4}$ energetically favorable under low energy CID conditions.

The formations of ions via ejection of low mass charged particles (the observed $\mathrm{m} / \mathrm{z}$ values are consistent with hydride ions), observed for Structures D and $\mathrm{E}$, are likely to be extreme cases of processes that occur to a small extent for all sulfated carbohydrates during negative CID. At the present time, observation of the highest HLGAG ion charge states has been limited to ion trap mass spectrometers equipped with heated capillary electrospray sources. It has not been possible to observe highly charged, deprotonated HLGAG ions using presently available quadrupole orthogonal acceleration time-of-flight mass spectrometers, probably because the desolvation of ions is too energetic and results in in-source fragmentation and the non-resonant CID process results in excessive fragmentation of deprotonated HLGAG ions.

These results show that the formation of glycosidic bond cleavages from HLGAG ions is balanced against that of competing processes, both for low and high charge states. For low charge states, losses of $\mathrm{SO}_{3}$ result in the most abundant product ions in the tandem mass spectra [23]. For high charge states, losses of equivalents of $\mathrm{H}_{2} \mathrm{SO}_{4}$ from the precursor ion and from product ions derived from scission of glycosidic bonds represent unproductive fragmentation channels with respect to the useful information available from the tandem mass spectra.

In practical terms, because of the fragmentation pathways competing with glycosidic bond cleavages, a product ion may only be considered structurally useful when a complementary fragment ion is detected. Complementary ions are those whose extracted neutral masses sum to the neutral mass of the precursor ion. For such pairs, it is certain that no losses of sulfate groups have occurred in the tandem mass spectra. In addition, the results shown here demonstrate that increased structural information may be achieved by subsequent stages of MS on the abundant glycosidic bond product ions. Such ions increase the likelihood of identifying complementary pairs by increasing the number of cleaved glycosidic bonds.

With this approach, structural analysis of HLGAG ions requires $\mathrm{MS}^{\mathrm{n}}$ analysis on all observed charge states, selecting the two or three most abundant product ions in the $\mathrm{MS}^{2}$ stages for subsequent fragmentation. If necessary, solvent conditions may be changed to favor the formation of different charge states. By combining all data, complete glycosidic bond coverage may be obtained. Measures taken to stabilize sulfate groups without increasing charge state may result in increase of the information value of a single stage of MS and thus make tandem mass spectrometric analysis of HLGAG more facile. The investigation of metal cations for this purpose is the subject of ongoing research in the authors' laboratory.

\section{Acknowledgments}

The authors gratefully acknowledge the following grant support: NIH/NCRR P41 RR1088, NIH/NHLBI RO1 HL74197, Neose Technologies GRANT program. Bruker Daltonics donated the Esquire 3000 mass spectrometer used in this work.

\section{References}

1. Bernfield, M.; Gotte, M.; Park, P. W.; Reizes, O.; Fitzgerald, M. L.; Lincecum, J.; Zako, M. Functions of Cell Surface Heparan Sulfate Proteoglycans. Annu. Rev. Biochem. 1999, 68, 729-777.

2. Rosenberg, R. D.; Shworak, N. W.; Liu, J.; Schwartz, J. J.; Zhang, L. Heparan Sulfate Proteoglycans of the Cardiovascular System. Specific Structures Emerge But How is Synthesis Regulated? J. Clin. Invest. 1997, 99, 2062-2070.

3. Conrad, H. E. Heparin Binding Proteins; Academic Press: New York, 1998.

4. Salmivirta, M.; Lidholt, K.; Lindahl, U. Heparan Sulfate: A Piece of Information. FASEB J. 1996, 10, 1270-1279.

5. Gallagher, J. T.; Walker, A. Molecular Distinctions Between Heparan Sulphate and Heparin. Analysis of Sulphation Patterns Indicates that Heparan Sulphate and Heparin are Separate Families of N-Sulphated Polysaccharides. Biochem. J. 1985, 230, 665-674.

6. Carr, S. A.; Reinhold, V. N. Structural Characterization of Sulfated Glycosaminoglycans by Fast Atom Bombardment Mass Spectrometry: Application to Chondroitin Sulfate. J. Carbohydr. Chem. 1984, 3, 381-401.

7. Reinhold, V. N.; Carr, S. A.; Green, B. N.; Petitou, M.; Choay, J.; Sinay, P. Structural Characterization of Sulfated Glycosaminoglycans by Fast Atom Bombardment Mass Spectrometry: Application to Heparin Fragments Prepared by Chemical Synthesis. Carbohydr. Res. 1987, 161, 305-313.

8. Dell, A.; Rogers, M.; Thomas-Oates, J.; Huckerby, T.; Sanderson, P.; Nieduszynski, I. Fast-Atom-Bombardment Mass-Spectrometric Strategies for Sequencing Sulfated Oligosaccharides. Carbohydr. Res. 1988, 179, 7-19.

9. Khoo, K. H.; Morris, H. R.; McDowell, R. A.; Dell, A.; Maccarana, M.; Lindahl, U. FABMS/Derivatization Strategies for the Analysis of Heparin-Derived Oligosaccharides. Carbohydr. Res. 1993, 244, 205-223.

10. Mawhinney, T. P.; Chance, D. L. Structural Elucidation by Fast-Atom-Bombardment Mass-Spectrometry of Multisulfated Oligosaccharides Isolated from Human Respiratory Mucous Glycoproteins. J. Carbohydr. Chem. 1994, 13, 825-840.

11. Juhasz, P.; Biemann, K. Mass Spectrometric Molecular-Weight Determination of Highly Acidic Compounds of Biological Significance via Their Complexes with Basic Polypeptides. Proc. Natl. Acad. Sci. U.S.A. 1994, 91, 4333-4337. 
12. Juhasz, P.; Biemann, K. Utility of Noncovalent Complexes in the Matrix-Assisted Laser Desorption Ionization Mass Spectrometry of Heparin-Derived Oligosaccharides. Carbohydr. Res. 1995, 270, 131-147.

13. Rhomberg, A. J.; Shriver, Z.; Biemann, K.; Sasisekharan, R. Mass Spectrometric Evidence for the Enzymatic Mechanism of the Depolymerization of Heparin-Like Glycosaminoglycans by Heparinase II. Proc. Natl. Acad. Sci. U.S.A. 1998, 95, 12232 12237.

14. Shriver, Z.; Sundaram, M.; Venkataraman, G.; Fareed, J.; Linhardt, R.; Biemann, K.; Sasisekharan, R. Cleavage of the Antithrombin III Binding Site in Heparin by Heparinases and its Implication in the Generation of Low Molecular Weight Heparin. Proc. Natl. Acad. Sci. U.S.A. 2000, 97, 10365-10370.

15. Venkataraman, G.; Shriver, Z.; Raman, R.; Sasisekharan, R. Sequencing Complex Polysaccharides. Science 1999, 286, 537542.

16. Rhomberg, A. J.; Ernst, S.; Sasisekharan, R.; Biemann, K. Mass Spectrometric and Capillary Electrophoretic Investigation of the Enzymatic Degradation of Heparin-Like Glycosaminoglycans. Proc. Natl. Acad. Sci. U.S.A. 1998, 95, 4176-4181.

17. Ernst, S., Rhomberg, A. J.; Biemann, K.; Sasisekharan, R. Direct Evidence for a Predominantly Exolytic Processive Mechanism for Depolymerization of Heparin-Like Glycosaminoglycans by Heparinase I. Proc. Natl. Acad. Sci. U.S.A. 1998, 95, 41824187.

18. Takagaki, K.; Kojima, K.; Majima, M.; Nakamura, T.; Kato, I.; Endo, M. Ion-Spray Mass Spectrometric Analysis of Glycosaminoglycan Oligosaccharides. Glycoconj. J. 1992, 9, 174-179.

19. Ii, T.; Ohashi, Y.; Nunomura, S.; Ogawa, T.; Nagai, Y. Fast Atom Bombardment and Electrospray Ionization Tandem Mass Spectrometry of Sulfated Lewis(X) Trisaccharides. J. Biochem. Tokyo 1995, 118, 526-533.

20. Chai, W.; Luo, J.; Lim, C. K.; Lawson, A. M. Characterization of Heparin Oligosaccharide Mixtures as Ammonium Salts Using Electrospray Mass Spectrometry. Anal. Chem. 1998, 70, 2060-2066.

21. Zaia, J.; McClellan, J. E.; Costello, C. E. Tandem Mass Spectrometric Determination of the 4S/6S Sulfation Sequence in Chondroitin Sulfate Oligosaccharides. Anal. Chem. 2001, 73, 6030-6039.

22. McClellan, J. M.; Costello, C. E.; O'Connor, P. B.; Zaia, J. Influence of Charge State on Product Ion Mass Spectra and the Determination of 4S/6S Sulfation Sequence of Chondroitin Sulfate Oligosaccharides. Anal. Chem. 2002, 74, 3760-3771.
23. Zaia, J.; Costello, C. E. Tandem Mass Spectrometry of Sulfated Heparin-Like Glycosaminoglycan Oligosaccharides. Anal. Chem. 2003, 75, 2445-2455.

24. Orgueira, H. A.; Bartolozzi, A.; Schell, P.; Litjens, R. E.; Palmacci, E. R.; Seeberger, P. H. Modular Synthesis of Heparin Oligosaccharides. Chemistry 2003, 9, 140-169.

25. Gunay, N. S.; Tadano-Aritomi, K.; Toida, T.; Ishizuka, I.; Linhardt, R. Evaluation of Counterions for Electrospray Ionization Mass Spectral Analysis of a Highly Sulfated Carbohydrate, Sucrose Octasulfate. Anal. Chem. 2003, 75, 3226-3231.

26. Siegel, M. M.; Tabei, K.; Kagan, M. Z.; Vlahov, I. R.; Hileman, R. E.; Linhardt, R. Polysulfated Carbohydrates Analyzed as Ion-Paired Complexes with Basic Peptides and Proteins Using Electrospray Negative Ionization Mass Spectrometry. J. Mass Spectrom. 1997, 32, 760-772.

27. Duffin, K. L.; Welply, J. K.; Huang, E.; Henion, J. D. Characterization of $N$-Linked Oligosaccharides by Electrospray and Tandem Mass Spectrometry. Anal. Chem. 1992, 64, 1440-1448.

28. Stephenson, J. L.; McLuckey, S. A. Charge Reduction of Oligonucleotide Anions via Gas-Phase Electron Transfer to Xenon Cations. Rapid Commun. Mass Spectrom. 1997, 11, 875880.

29. Stephenson, J. L.; VanBerkel, G. J.; McLuckey, S. A. Ion-Ion Proton Transfer Reactions of Bio-Ions Involving Noncovalent Interactions: Holomyoglobin. J. Am. Soc. Mass Spectrom. 1997, $8,637-644$

30. Wells, J. M.; Chrisman, P. A.; McLuckey, S. A. “Dueling” ESI: Instrumentation to Study Ion-Ion Reactions of ElectrosprayGenerated Cations and Anions. J. Am. Soc. Mass Spectrom. 2002, 13, 614-622.

31. Hofmeister, G. E.; Zhou, Z.; Leary, J. A. Linkage Position Determination in Lithium-Cationized Disaccharides-Tandem Mass-Spectrometry and Semiempirical Calculations. J. Am. Chem. Soc. 1991, 113, 5964-5970.

32. Gillece-Castro, B. L.; Burlingame, A. L. Oligosaccharide Characterization with High-Energy Collision-Induced Dissociation Mass Spectrometry. Methods Enzymol. 1990, 193, 689-712.

33. Tseng, K.; Lindsay, L. L.; Penn, S.; Hedrick, J. L.; Lebrilla, C. B. Characterization of Neutral Oligosaccharide-Alditols from Xenopus Laevis Egg Jelly Coats by Matrix-Assisted Laser Desorption Fourier Transform Mass Spectrometry. Anal. Biochem. $1997,250,18-28$.

34. Konig, S.; Leary, J. A. Evidence for Linkage Position Determination in Cobalt Coordinated Pentasaccharides Using Ion Trap Mass Spectrometry. J. Am. Soc. Mass Spectrom. 1998, 9, 1125-1134. 